\title{
É tempo de transformação na educação: docência, tecnologias digitais e pandemia
}

\section{It's time for transfomation in education: teaching, digital technologies and pandemics}

\author{
${ }^{1}$ Vivian Martins vivian.martinst@gmail.com \\ ${ }^{2}$ Bárbara Rodrigues de Castro
}

\section{RESUMO}

A reconfiguração da educação brasileira com a pandemia de Covid-19 é o contexto do presente artigo. O objetivo é compreender, a partir de uma etnografia online, os processos de significação de docentes da educação básica a respeito do ensino remoto ao longo do distanciamento social. O método escolhido para a investigação foi a etnografia online, decorrente da percepção das pesquisadoras sobre a crescente disseminação de narrativas sobre a temática em comunidades virtuais. Os praticantes da pesquisa são professores da educação básica criadores de narrativas digitais importantes para a compreensão do fenômeno que se apresenta (ensino remoto). O campo de pesquisa é composto pelas redes sociais da internet, em especial quatro comunidades virtuais no Facebook: academia pandêmica, Educação - vagas, Vagas para professores RJ e Profissão=Professora. Como resultado da pesquisa, reunimos algumas categorias que emergiram de forma recorrente no campo de pesquisa. Apresentamos algumas ações que pensamos poder contribuir para uma mudança no paradigma educacional pós-pandemia.

Palavras-chave: Tecnologias na educação. Ensino remoto. Distanciamento social. Etnografia Online.

\begin{abstract}
The reconfiguration of Brazilian education with the Covid-19 pandemic is the context of this article. The objective is to understand, from an online ethnography, the processes of the teachers' signification regarding teaching remotely during social distance. The method chosen for the investigation was online ethnography, resulting from the researchers' perception of the growing dissemination of teachers' narratives in virtual communities. K-12 teachers'digital narratives contribute to the understanding of the phenomenon (remote learning). The research field is composed of four virtual communities on Facebook: pandemic academy, Education - vacancies, Vacancies for teachers RJ and Profession=Teacher. As a result, we gathered some categories that emerged recurrently in the research field. As a proposal, we present some actions that we think contribute to change the post-pandemic educational paradigm.
\end{abstract}

Keywords: Educational technologies. Remote learning. Social distancing. Online Ethnography.

1 Doutoranda do Programa de Pós-graduação em Educação da Universidade do Estado do Rio de Janeiro (UERJ). Instituto Federal do Rio de Janeiro.

2 Cursando pós graduação pela UNINTER no curso Educomunicação e Tecnologia -Professora de ensino fundamental na rede municipal da cidade do Rio de Janeiro. 


\title{
1 PENSAMENTOS INTRODUTÓRIOS
}

\begin{abstract}
Nutrindo-se de mudanças, o tempo de trânsito é mais do que simples mudança. Ele implica realmente nesta marcha acelerada que faz a sociedade à procura de novos temas e de novas tarefas. E se todo Trânsito é mudança, nem toda mudança é Trânsito. As mudanças se processam numa mesma unidade de tempo histórico qualitativamente invariável, sem afetá-la profundamente. É que elas se verificam pelo jogo normal de alterações sociais resultantes da própria busca de plenitude que o homem tende a dar aos temas. Quando, porém, estes temas iniciam o seu esvaziamento e começam a perder significação e novos temas emergem, é sinal de que a sociedade começa a passagem para outra época. Nestas fases, repita-se, mais do que nunca, se faz indispensável a integração do homem. Sua capacidade de apreender o mistério das mudanças, sem o que será delas um simples joguete. FREIRE, 1967, p. 46
\end{abstract}

Vivemos tempos de mudança, mudança nas relações, no meio ambiente, na economia, na fruição artística, no âmbito profissional, na saúde, na informação, nos serviços, no turismo, na educação, nas formas de ser e estar no mundo. Freire (1967) menciona um tempo de trânsito, em que as pessoas precisam se integrar e aprender sobre a mudança para não se tornarem joguetes. Nessa perspectiva, torna-se importante que as pessoas se insiram nas mudanças. Sendo a educação fator primordial para esse processo: "a educação, por isso, na fase de trânsito que vivíamos se fazia uma tarefa altamente importante. A sua força decorreria, sobretudo, da capacidade que tivéssemos de nos incorporarmos ao dinamismo da época do trânsito” (FREIRE, 1967, p. 47).

Freire (1967) fala em outro contexto de mudança, da difícil década de 60 para o mundo. Contudo, suas palavras desempenham um papel impulsionador para reflexão sobre o momento que vivemos hoje. Estamos em meio a uma pandemia provocada pelo Coronavírus, vírus que causa infecções respiratórias, provocando a doença denominada COVID-19. A transmissão acontece de uma pessoa doente para outra pela proximidade, sem o uso de barreiras físicas e através de superfícies contaminadas (MINISTÉRIO DA SAÚDE, 2020). Frente a tal contexto, entre as recomendações para evitar a transmissão, tem-se o distanciamento social, que afetou todos os setores da sociedade. Dessa forma, foi necessário suspender as aulas nas instituições de ensino presenciais na maior parte dos países.

De acordo com monitoramento da Organização das Nações Unidas para a Educação, a Ciência e a Cultura (UNESCO, 2020), em 22 de abril de 2020 eram 1,579,634,506 estudantes afetados, ou seja, 90.2\% do total de estudantes matriculados no mundo. Em 05 de março de 2021 esse número reduziu para 8.3\% do total de estudantes matriculados (UNESCO, 2021). "Mais de 150 países implementaram fechamentos em todo o país, provocando impacto em mais de $80 \%$ da população estudantil do mundo" (UNESCO, 2020). Ressaltamos que as adversidades não são as mesmas em todos os países, cada realidade social, econômica e educacional possui suas particularidades e a realidade brasileira é o nosso recorte. Também levamos em consideração olhar dados de 2020 e 2021 para compreender o movimento que o ensino remoto fez ao longo de um ano de pandemia.

Com a suspensão das atividades presenciais, muitas iniciativas de escolas públicas e privadas foram instauradas para a inclusão de propostas educacionais com o uso de tecnologias. O Conselho Nacional de Educação (CNE) publicou em 28 de abril de 2020, homologado pelo Ministério da Educação (MEC) em $1^{\circ}$ de junho de 2020, parecer favorável à possibilidade de cômputo de atividades não presenciais para fins de cumprimento da carga horária mínima anual, em razão da pandemia da COVID-19.

Podemos nos deixar levar pelo fascínio que a explosão tecnológica tem causado e afirmar que a simples introdução das tecnologias nas escolas significaria melhoria na qualidade do ensino. Contudo, além de considerar a exclusão digital, é preciso pensar em um planejamento pedagógico direcionado para esse tipo de prática. Não basta realizar a transposição didática do presencial para a educação a distância, é necessário desenvolver ambiências formacionais com metodologias adequadas.

Diante do exposto, desenvolvemos uma pesquisa que apresenta como objetivo: compreender, a partir de uma etnografia online, os processos de significação de docentes da educação básica a respeito do ensino remoto ao 
longo do distanciamento social. A etnografia online é um método de pesquisa qualitativa que busca compreender profundamente a vida social e cultural de comunidades, instituições e outros ambientes, especificamente análises em ambientes virtuais. Assim, consideramos as narrativas publicadas nas redes sociais da internet como fontes de pesquisa. Os praticantes (CERTEAU, 1994) ciberculturais da pesquisa são professores da educação básica que criam e compartilham narrativas digitais relacionadas ao novo formato que a educação assumiu após o Coronavírus.

O presente artigo foi desenvolvido em tópicos específicos: esta introdução, apresentando o contexto, o objetivo e as opções teórico-metodológicas da pesquisa; na seção 2, como as tecnologias transversalizam nossas ações cotidianas; na seção 3, os princípios metodológicos que percorreremos no desenvolvimento da pesquisa, com a etnografia online; na seção 4, a apresentação das narrativas dos praticantes e os resultados da pesquisa; e, por fim, algumas considerações finais, com a síntese dos conteúdos abordados.

\section{AS TECNOLOGIAS NO COTIDIANO CIBERCULTURAL}

Se pensarmos a tecnologia como modificadora do meio onde vivem os homens, devemos pensar que tudo é tecnologia, desde uma pedra (idade das pedras ou pré-história) usada para utensílios e armas, até os mais modernos computadores. A partir do século XVIII, com a Revolução Industrial e a ascensão do capitalismo, as tecnologias desenvolvem-se em um ritmo acelerado, até atingir aos dias contemporâneos onde vemos a tecnologia apresentando características muito mais potentes. Hoje vivemos na Cibercultura, que segundo Lévy (1999) é "o conjunto de técnicas (materiais e intelectuais), de práticas, de atitudes, de modos de pensamento e de valores que se desenvolvem juntamente com o crescimento do ciberespaço.”, que modifica nossos hábitos e as formas de estar no mundo.

A cibercultura foi constituída a partir da informatização da sociedade, quando os computadores passaram a ser pessoais e a maior parte da população obteve acesso ao que antes era restrito às instituições e aos governos. No Brasil, a cibercultura se populariza com a emergência da microinformática. As pessoas passaram a habitar o ciberespaço com a inserção do digital na sociedade, associando-se a redes diversas, em um espaço virtual que agrega pessoas em situações interativas síncronas e assíncronas.

Com o advento da web 2.0 (SANTOS, 2014), houve a possibilidade de o usuário intervir de forma mais intuitiva no conteúdo do ciberespaço. As interfaces comunicacionais como os blogs possibilitaram que os usuários que não possuíam conhecimentos aprofundados de informática inserissem narrativas textuais, imagéticas, sonoras e audiovisuais, povoando o ciberespaço em uma velocidade não imaginável anteriormente. Na proporção em que as conexões aumentavam, crescia a interatividade na rede, com as práticas sociais tomando conta do cotidiano dos praticantes ciberculturais, possibilitando a atuação conectada. As autorias e as coautorias foram potencializadas: na web 1.0, os sites eram repositórios de conteúdos criados por pessoas especializadas, diferente da web 2.0, onde pessoas sem largos conhecimentos em informática poderiam criar conteúdos e disponibilizar de forma intuitiva em blogs e redes sociais.

Dessa maneira, a autoria foi potencializada, o praticante pode desenvolver múltiplas funções sem a necessidade de recursos muito elaborados, principalmente a partir da convergência de mídias encontrada nos dispositivos móveis, facilitando a produção e o compartilhamento de situações cotidianas. "As distinções de status entre produtores, consumidores, críticos, editores e gestores da midiateca se apagam em proveito de uma série contínua de intervenções onde cada um pode desempenhar o papel que desejar”, observam Lemos e Lévy (2010, p. 11).

A partir da web 3.0, da internet inteligente ou web semântica, os dados disponíveis na internet passaram a ser organizados "por meio da compreensão da linguagem humana, pelas máquinas, na recuperação da informação, sem que o usuário precise dominar refinadas estratégias de linguagem ou conhecimento de máquinas de busca” (Loth; Pretto; Oliveira; Zschornack, 2019, p. 39). Dessa forma, nossos dados viram um produto de ex- 
trema relevância para empresas de todos os setores e com diversas finalidades, como para educação, marketing, saúde, segurança, entre outros. Precisamos estar atentos a esses movimentos.

Neste contexto, aparece um novo formato de educação, no qual giz, quadro e livros não são mais os únicos instrumentos para dar aulas que os professores possuem, necessitando assim desenvolver um conjunto de atividades didático-pedagógicas a partir das tecnologias disponíveis, as que os alunos dispõem em suas residências. Como essa realidade pegou a todos de surpresa, muitos não estavam formados para desenvolver suas aulas de forma remota, criar recursos educacionais digitais ou se comunicar virtualmente com os alunos. Diante de tal cenário, a realidade profissional dos professores virou de ponta cabeça e as narrativas sobre tais vivências se disseminaram nas redes sociais, proporcionando um campo fecundo para uma etnografia online, temática abordada a seguir.

\section{A ETNOGRAFIA ONLINE}

Com o intuito de compreender os movimentos culturais em rede e ambientes de interações sociais digitais, surge a etnografia online. Observamos "como as pessoas usam a internet, mas também as práticas que tornam os usos da internet significativos em contextos locais” (MERCADO, 2012, p. 173). Sendo assim, buscamos entender como professores dão sentido aos usos em rede, por vezes narrando ações cotidianas, trabalhando ou as utilizando para diferentes fins. Compreendermos a internet como "artefato cultural” (HINE, 2000), "um produto da cultura: uma tecnologia que foi produzida por pessoas particulares com objetivos e prioridades situadas contextualmente" (HINE, 2000, p. 9). Nosso intuito é ampliar o olhar para as significações de professores nas redes, em especial, a respeito de suas realidades educacionais no contexto pandêmico. Ressaltamos que as investigações de abordagens etnográficas na internet são comumente chamadas de netnografia, etnografia virtual, webnografia, etnografia digital ou etnografia online. Optamos pelo termo etnografia online no presente trabalho.

Realizamos alguns passos nessa etnografia online, não necessariamente fixos, mas que inspiram as ações: o questionamento inicial que encoraja a investigação e a definição do tema, com o desenvolvimento dos objetivos da pesquisa; a seleção em grau de relevância para o objeto de pesquisa dos ambientes online que são analisados; as questões éticas envolvendo o tipo e os sujeitos da pesquisa; ao iniciar o campo de pesquisa, há a definição do grau de inserção do pesquisador, o mergulho no ambiente a ser pesquisado, com a observação, a seleção e o registro dos dados que fazem mais sentido para ele; a verificação se os participantes aceitam ou não participar da pesquisa, através de suas narrativas; e a conversa com os dados, por meio de uma triangulação relacionando a teoria, com os dados obtidos e a interpretação do pesquisador, que lança seu olhar e conversa com as múltiplas referências que o transversalizam.

Destacamos que o respeito aos participantes da pesquisa, em suas vontades, direitos e benefícios é primordial. É na relação com o outro e com o social que a ética nas ciências humanas se insinua. Do diálogo e da compreensão de que a produção - ou usos, táticas e astúcias, como nos ensina Certeau (1994) - do outro seja tão importante quanto a dos pesquisadores ou teóricos da área da educação, tratando com horizontalidade o que o cotidiano nos mostra, bonito ou não, mas verdadeiro. Além da qualidade das pesquisas que considerem a responsabilidade, a autenticidade, a justiça e outros valores éticos e morais que configuram a tônica para investigações sérias e implicadas.

Buscamos nessa pesquisa compreender a complexidade da situação atual, uma pandemia e os reflexos do distanciamento social para professores da educação básica, através de seus relatos nas comunidades online, tendo como base dados reais e a compreensão de atitudes, motivações e expectativas diante do cenário atual. O campo da pesquisa é composto por comunidades sociais no Facebook, onde grande parte dos participantes são professores, estudiosos e profissionais diversos da área de educação. Buscamos compreender a vida social e cultural de comunidades de professores no contexto de ressignificação da educação. 
O período de participação no campo de pesquisa foi de um ano, entre março de 2020 e março de 2021. Selecionamos quatro comunidades no Facebook: academia pandêmica, Educação - vagas, Vagas para professores RJ e Profissão=Professora. A escolha deles se deu em função da relevância de suas postagens, após perceber que elas originavam uma grande quantidade de narrativas por professores da educação básica (nosso direcionamento para o estudo).

Tal percepção ocorreu a partir da imersão contínua enquanto praticantes ciberculturais. Nesse sentido, não vamos ao campo de pesquisa coletar dados, estamos no campo em nossos cotidianos, com olhar aguçado para a investigação, já que no feed de notícias apareciam debates interessantes, proporcionando reflexões sobre a pesquisa. Optamos pela observação não participante, onde os pesquisadores atuaram como espectadores dos grupos, buscando a redução das influências e modificações que poderiam ocorrer nas narrativas.

O diário de campo foi realizado através do Whatsapp, em um grupo entre os pesquisadores, onde eram enviados registros necessários para o desenvolvimento da pesquisa, como notícias e publicações científicas relacionadas ao tema, reflexões dos pesquisadores para a elaboração do artigo, regulamentações necessárias à compreensão do contexto atual, imagens divulgadas em rede, narrativas dos praticantes ciberculturais e observações de interações mediadas pelas ferramentas comunicacionais, entre outros dados, de forma a reunir em um espaço único para que não se perdesse nada.

Foram selecionadas 105 narrativas de professores para a análise final, alguns relatos bem extensos e outros mais sucintos, mas sem organização e sistematização dos dados, facilmente seriam perdidos. Com a compreensão dos processos de significações das narrativas, alinhamos em frequências, definições; unidades de texto ilustrativas que se aplicam a cada categoria. Com a seleção das narrativas finais, presentes na composição do texto a seguir, há a conversa com os autores para a apresentação dos resultados da pesquisa.

\section{NARRATIVAS DIGITAIS DE PROFESSORES EM MEIO AO ENSINO REMOTO}

As categorias podem ser criadas, de acordo com Mercado (2012, p. 180), inferindo-se das narrativas "diferentes concepções de mundo, de escola, de indivíduo, sociedade. A transparência dos dados coletados exige do pesquisador a construção de registros explicativos dos procedimentos e decisões tomadas no curso da análise de conteúdo”. Dessa forma, abordaremos no quadro 1 as narrativas docentes em redes sociais da internet, realizando a categorização por temas dos assuntos mais abordados, que se tornaram recorrente nos debates. E, por fim, análises de tais narrativas, dialogando com o referencial teórico.

\section{Quadro 1. Narrativas docentes em redes sociais da internet}

\begin{tabular}{|l|l|}
\hline Temas & Narrativas \\
\hline $\begin{array}{l}\text { Repensar o currículo } \\
\text { para uma educação } \\
\text { humanista }\end{array}$ & $\begin{array}{l}\text { "Eu penso que o equívoco está em propor uma continuidade, transpor a rotina da escola para } \\
\text { casa é delírio! É preciso tempo e estudo para encontrar e se encontrar nessa nova forma de } \\
\text { interação. É preciso repensar conteúdos e formatos. É tempo de descontinuidade. Precisamos } \\
\text { parar esse desejo de transformar o caos em normalidade, quase que um anestésico para não } \\
\text { sentir. É preciso respiro para experimentarmos novas pedagogias, menos conteudistas e mais } \\
\text { humanistas." (Débora) }\end{array}$ \\
\hline $\begin{array}{l}\text { Precarização da } \\
\text { profissão docente }\end{array}$ & $\begin{array}{l}\text { "Não aguento mais e ainda por cima só recebi um adiantamento, ou melhor, um vale que } \\
\text { não deu nem para pagar a internet. Mas a carga de trabalho só aumentou. Desanimada e } \\
\text { desmotivada."(Nanda) } \\
\text { "Fora que as demissões de professores já começaram... Infelizmente nossa classe vai sentir a } \\
\text { desvalorização do nosso trabalho nessa situação! Com muita fé que esse momento vai passar, se } \\
\text { não for isso vamos pirar! Se cuidem!"(Renata) }\end{array}$ \\
\hline $\begin{array}{l}\text { Saúde dos } \\
\text { professores }\end{array}$ & $\begin{array}{l}\text { confesso que estou pedindo pra ter um descanso (férias antecipadas, se for o caso), pois o meu } \\
\text { corpo inteiro dói. Acordo de madrugada com dores e todos os dias sinto dor de cabeça.” (Pamella) }\end{array}$ \\
\hline
\end{tabular}




\begin{tabular}{|c|c|}
\hline $\begin{array}{l}\text { Exclusão social } \\
\text { - Estudantes } \\
\text { sem acesso aos } \\
\text { ambientes virtuais de } \\
\text { aprendizagem }\end{array}$ & $\begin{array}{l}\text { "Relatos de estudantes também têm sido coletados e diversos deles confirmam a dificuldade para } \\
\text { estar online no momento das aulas e os motivos são os mais diversos: falta de memória no celular, } \\
\text { ausência de dados móveis ou Wi-Fi, impossibilidade do uso destas tecnologias por precisarem } \\
\text { compartilhar um mesmo aparelho, aparelhos obsoletos, a ausência destes, deixando latente } \\
\text { que para uma aula online é necessário possuir minimamente um notebook, netbook ou PC.” } \\
\text { (Produtores da página do Facebook EaD na Educação Básica é Exclusão) }\end{array}$ \\
\hline $\begin{array}{l}\text { Lógica conteudista da } \\
\text { educação- Produção } \\
\text { de vídeos com foco } \\
\text { na transmissão de } \\
\text { conteúdo }\end{array}$ & $\begin{array}{l}\text { “(...) Eu vejo que quando se trata de Tecnologia em escola pública, nem sempre o problema é a } \\
\text { falta de infraestrutura, mas sim a preparação do Professor. Os alunos estão sendo bombardeados } \\
\text { de videoconferências e vídeos, falta de cuidado e planejamento com o que está sendo transmitido } \\
\text { ao aluno.” (Paulo Henrique) }\end{array}$ \\
\hline $\begin{array}{l}\text { As tecnologias } \\
\text { contribuindo para o } \\
\text { distanciamento social } \\
\text { - Evitar o retorno ao } \\
\text { presencial }\end{array}$ & $\begin{array}{l}\text { "Entendo que o sonho de uma volta à normalidade presencial deve ser mantido, mas enquanto } \\
\text { as condições materiais não se dão, a comunidade acadêmica poderia resignar-se a continuar sua } \\
\text { belíssima história com os recursos tecnológicos disponíveis capazes de fazer acontecer o ensino- } \\
\text { aprendizagem com a segurança necessária.” (Paulo) }\end{array}$ \\
\hline $\begin{array}{l}\text { Sobrecarga de } \\
\text { trabalho para a } \\
\text { produção de recursos } \\
\text { educacionais }\end{array}$ & $\begin{array}{l}\text { “(...) Hoje, para gravar uma aula de } 25 \text { minutos, para UMA turma eu demoro - entre fazer a aula, } \\
\text { gravar e editar - um dia, um dia e meio. Agora é só fazer as contas... Com } 21 \text { turmas, quanto } \\
\text { tempo eu perco na frente do computador? } \\
\text { Some isso ao fato de eu não saber, e ter que procurar tutoriais na internet (...)”. (Érica) }\end{array}$ \\
\hline $\begin{array}{l}\text { Dificuldades } \\
\text { financeiras }\end{array}$ & $\begin{array}{l}\text { "Não consigo arcar com as minhas despesas e da minha mãe e para comprar um computador } \\
\text { agora está difícil, nem para pagar minha internet está dando. Tem alguém se sentindo assim sem } \\
\text { direito de escolha? Como professor."(Elizabeth) }\end{array}$ \\
\hline $\begin{array}{l}\text { Relação entre } \\
\text { professores e } \\
\text { responsáveis }\end{array}$ & $\begin{array}{l}\text { "Imagina nosso psicológico como está. Somos seres humanos, estamos expondo nossa casa, } \\
\text { nossa imagem. Estamos nos esforçando, mas, eles só sabem criticar nosso trabalho. Não tivemos } \\
\text { treinamento. Nem todo professor tem um bom computador, uma câmera. Queria ver se como esses } \\
\text { pais que ficam criticando se sairiam fazendo o nosso trabalho."(Kelli) }\end{array}$ \\
\hline $\begin{array}{l}\text { Táticas de praticantes } \\
\text { para driblar a falta de } \\
\text { dados de internet }\end{array}$ & $\begin{array}{l}\text { “Aqui não estamos gravando vídeos já que muitos alunos tem pacotes pequenos de internet. } \\
\text { Apenas colocamos sugestões de vídeos para quem puder acessar. Ou seja, é tudo em PDF pelo } \\
\text { Google Classroom.” (Katylen) }\end{array}$ \\
\hline $\begin{array}{l}\text { Entrelaçamento entre } \\
\text { a vida profissional e a } \\
\text { pessoal }\end{array}$ & $\begin{array}{l}\text { "Nunca meu celular tocou tanto!! Muitos alunos perguntando, fora do horário da aula, deixo no } \\
\text { silencioso a noite pra dormir. Vida profissional e pessoal muito misturadas...”(Taila) }\end{array}$ \\
\hline $\begin{array}{l}\text { Retorno seguro das } \\
\text { aulas presenciais }\end{array}$ & $\begin{array}{l}\text { “Tivemos alunos que abandonaram a escola pública pela particular e estão frustrados com a } \\
\text { volta para escola. São poucos alunos, todos sentados, sem interação social. É utopia imaginar que } \\
\text { tudo está normal. As UTI estão sem vagas, não tem vacinas para crianças e os adultos ainda não } \\
\text { foram vacinados. } \\
\text { Oro a Deus para que tudo volte a normal e possamos trabalhar com segurança.” (Fabiana) } \\
\text { “Tenho duas meninas e apesar de todas as dificuldades com as aulas on-line (delas e as minhas, } \\
\text { afinal também sou professora), nenhuma das duas irá para a escola enquanto não for seguro. } \\
\text { Já eu sou obrigada a ir, procuro me cuidar de todas as formas, mas o medo é a insegurança são } \\
\text { parceiras constantes já que o governo não nos dá condições de trabalho, mas exigem que façamos } \\
\text { o nosso!” (Regiani) }\end{array}$ \\
\hline $\begin{array}{l}\text { Resiliência docente, } \\
\text { desafios profissionais } \\
\text { e superação }\end{array}$ & $\begin{array}{l}\text { "Ser Professor é sinônimo de resiliência, ou seja, ensina o q sabe, mas é flexível p aprender. Está } \\
\text { sempre em busca de desenvolver um excelente trabalho sem fugir dos desafios que são impostos à } \\
\text { sua profissão. Que Deus continue abençoando os professores!” (Graciete) } \\
\text { "Lógico e evidente que nesse momento a ciência é a parte mais importante (a área da saúde e } \\
\text { outros), mas eu estou para ver uma classe que supera tantas adversidades e consegue se superar... } \\
\text { Viva aos professores!” (Vanessa) }\end{array}$ \\
\hline
\end{tabular}

Entre uma centena de narrativas destacamos 13 temáticas abordadas de forma recorrente nas conversas entre professores pelas redes sociais da internet. Ressaltamos que a presente pesquisa não pretende trazer uma 
abordagem completa sobre a temática, pois escolhas são feitas, buscando uma fonte para reflexão por todos nós, o recorte para os temas levam em consideração as experiências de vida e de formação dos pesquisadores e em um período curto, porém intenso, de tempo ao longo do distanciamento social. Também não pretendemos nos distanciar do objeto, pois também somos professores e estamos carregados de subjetividades, atravessados pelo tema e pela vivência em um contexto de pandemia.

Algumas questões ficaram latentes com a análise das narrativas: para quem e com qual finalidade a educação é praticada nas escolas? Como superar a lógica conteudista e a transmissão de conteúdos enraizados na educação? De que forma buscar a valorização da profissão docente? Como desenvolver práticas pedagógicas que alcancem uma maior parcela dos estudantes, considerando suas dificuldades com infraestrutura tecnológica? E, por fim, como pensar o retorno às atividades presenciais sem vacina e em um pós-pandemia repleto de insegurança e instabilidade emocional?

Um dos tópicos comentados é a respeito da exclusão social e como as desigualdades afetam diretamente os estudantes, pois muitos não encontram meios de acompanhar as aulas, seja por não dispor de equipamentos, ou por não possuir conexão. Sabemos que ainda há muito a se investir em relação à infraestrutura tecnológica no Brasil, algumas secretarias de educação estão investindo em canais de rádio e televisão, para alcançar de forma mais abrangente a população em idade escolar. Felizmente, podemos encontrar diferentes iniciativas, sensíveis às adversidades que a população brasileira vem passando. Contudo, precisamos estar atentos ao real significado de educação e se ela está sendo realmente praticada.

Percebemos nas narrativas dos docentes que não podemos ignorar as dificuldades de acesso de discentes, mas também dos próprios professores, vale ressaltar. O relato de Elizabeth a respeito das dificuldades financeiras reforça tal percepção. "Não consigo arcar com as minhas despesas e da minha mãe e para comprar um computador agora está difícil, nem para pagar minha internet está dando”. A esse respeito, Pretto, Bonilla e Sena (2020) pontuam:

\footnotetext{
Aos professores está sendo atribuída a responsabilidade de assumirem os custos da infraestrutura física e tecnológica, não planejada para o uso intensivo nos dias atuais. Parte-se do pressuposto de que os professores tenham (ou lhes obrigam a ter!) disponível em suas casas condições adequadas, como: espaço isolado, mobiliário ergonomicamente desenhado e equipamentos para que seja possível realizar, com comodidade e tranquilidade, as atividades a distância. No tocante às conexões, é importante considerar que a sua qualidade, já há muito vem sendo denunciada pelo coletivo Coalizão Direitos na Rede, uma vez que, mesmo com contratos privados de serviço de internet, são oferecidos pacotes com velocidades muito aquém daquelas contratadas (PRETTO; BONILLA; SENA, 2020, p. 10-11).
}

A crise ocasionada pelo distanciamento social acentua a quantidade de pessoas sem conseguir trabalhar e empresas de todos os tipos fechando. Uma das demandas pelo ensino remoto veio por parte das escolas particulares, no sentido de dar continuidade aos processos educativos, continuar recebendo as mensalidades, visando o não fechamento das escolas e/ou a demissão dos professores. Posteriormente, com o longo período de pandemia, ampliou para o setor público também.

A precarização da profissão docente é cada vez mais latente, os baixos salários impulsionam que profissionais desistam de sua profissão. A valorização desse profissional é crucial para a sociedade e não só no contexto atual, em todos os cenários possíveis. Quatro temas destacados no Quadro 1 estão envolvidos nesse debate: precarização da profissão docente, exclusão social, sobrecarga de trabalho e dificuldades financeiras.

Os trabalhadores precários, informais, ditos autónomos. Depois de quarenta anos de ataque aos direitos dos trabalhadores em todo o mundo por parte das políticas neoliberais, este grupo de trabalhadores é globalmente dominante, ainda que sejam muito significativas as diferenças de país para país. O que significará a quarentena para estes trabalhadores, que tendem a ser os mais rapidamente despedidos sempre que há uma crise económica? O sector de serviços, onde abundam, será uma das áreas mais afectadas pela quarentena (SANTOS, B., 2020, p. 16). 
No tocante aos grupos mais afetados e para quem a quarentena é mais difícil, Boaventura de Sousa Santos (2020) analisa grupos em que a vulnerabilidade se agrava com a quarentena, os trabalhadores do setor de serviços é um eles. As mulheres também são lembradas como um coletivo social em que a quarentena é particularmente difícil, e constatamos, de acordo com o Censo Escolar da Educação Básica (MEC, 2019), que grande parte dos profissionais da educação é formada por mulheres. Ampliando as atividades laborais duplamente no que diz respeito ao trabalho remoto.

Um tema recorrente nos debates nas comunidades habitadas por professores é o retorno seguro das aulas presenciais. $\mathrm{O}$ fato de ainda não termos vacina para todos e as escolas serem espaços de socialização e proximidade amedronta professores e familiares. A pressão para um retorno presencial vem de todos os lados, com discursos como: "lugar de criança é na escola”, “crianças estão tristes em casa”, familiares que precisam trabalhar, não têm onde "deixar" as crianças, "socialização comprometida" e tantos outros dilemas. Mesmo compreendendo tais demandas como legítimas, reforçamos a escola como um grande vetor de disseminação do vírus. Somos pró-vida, defendemos a manutenção das atividades não presenciais e a rápida ampliação da vacinação para um retorno seguro.

Outros dois pontos destacados nas narrativas dos praticantes da pesquisa são: repensar o currículo para uma educação humanista e alteração da lógica conteudista da educação com a produção de vídeos com foco na transmissão de conteúdo. Dentro de suas possibilidades, a escola pode usar o ciberespaço como um ambiente de produção de sentidos que auxilie na mediação da aquisição do saber, sendo o principal agente democratizador do acesso. O uso das tecnologias pelos professores pode ajudar em suas práticas educativas, e outros dizem ser até imprescindíveis em sua prática. Porém, precisamos estar atentos ao seguinte:

Educar é um processo complexo, que exige mudanças significativas, investimento na formação de professores, para o domínio dos processos de comunicação da relação pedagógica e o domínio das tecnologias. Só assim, poderemos avançar mais depressa, com a consciência de que, em educação, não é tão simples mudar, porque existe uma ligação com o passado, que é necessário manter, e uma visão do futuro, à qual devemos estar atentos (MORAN, 2007, p. 249).

Parafraseando Moran, educar é aprender a administrar processos onde, de um lado, você anda em direção à autonomia, à liberdade, e de outro, você procura sua identidade. Então, educar utilizando as tecnologias, não é somente utilizar essas interfaces, mas também dar-lhes outro significado. A busca pela cidadania, pela educação humanística e pela apreensão da realidade dos estudantes, para proporcionar saberes que façam sentido e que estejam conectados com seus cotidianos. Como nos mostra Moran, (2007, p. 106) “o importante, como educadores, é acreditarmos no potencial de aprendizagem pessoal, na capacidade de evoluir, de integrar sempre novas experiências e dimensões do cotidiano”. Ou como nos diria a praticante Debora, “(...) é preciso respiro para experimentarmos novas pedagogias, menos conteudistas e mais humanistas”.

Em uma explosão do ensino remoto, observamos que a lógica da transmissão de conteúdos está sendo praticada por muitas escolas, no nosso ponto de vista, equivocadamente. Com isso, gostaríamos de ressaltar que em nosso país tal fato não é um problema ocasionado pelo COVID-19, a lógica da educação já vinha por esse caminho e o distanciamento social reforçou, na pura transposição de aulas para o não presencial. Esse problema reflete como muitos de nós, profissionais da educação, temos entendido e praticado o funcionamento das escolas há bastante tempo. Observamos como demanda primordial nessas propostas remotas o foco no conteúdo a ser transmitido, com a gravação de videoaulas, o aumento súbito das lives e envio de apostilas. Como Paulo Henrique alerta: “(...) os alunos estão sendo bombardeados de videoconferências e vídeos (...)”. Esse fato nos oferece pistas importantes sobre mudanças necessárias na educação brasileira.

Mesmo havendo o uso de interfaces tecnológicas como a internet, por exemplo, dentro do ambiente escolar, muitas escolas contextualizam a utilização desses meios a partir das suas próprias concepções e não a partir da contextualização da realidade de seus alunos. Sabemos que as tecnologias digitais em rede são estruturantes da cultura em que vivemos, apesar da grande exclusão digital e das dificuldades que uma pandemia ocasiona. 
Então, antes de tudo, é preciso que haja toda uma reestruturação do projeto político da escola, para repensar a educação como um todo.

A lógica conteudista da educação está em flagrante diante da mera transposição didática de conteúdos da educação presencial para o não presencial, com olhar direcionado em grande parte para a transmissão e não para processos de subjetivação, interdisciplinaridade, construção conjunta, com um olhar direcionado para a autoria, a formação para a cidadania, a cultura contemporânea e um currículo integrado entre si e com as questões da sociedade em que as escolas estejam inseridas. Nesse sentido, mudança é a palavra de ordem, não só na educação, mas em todos os setores da sociedade, "a nova articulação pressupõe uma viragem epistemológica, cultural e ideológica que sustente as soluções políticas, económicas e sociais que garantam a continuidade da vida humana digna no planeta. Essa viragem tem múltiplas implicações” (SANTOS, B., 2020, p. 31-32).

Santos, B. (2020) fala em sermos mais livres e em uma viragem epistemológica, cultural e ideológica, Freire (1967), na epígrafe deste texto fala a respeito do tempo de trânsito, em que o homem precisa se integrar e aprender sobre a mudança. Acrescentamos que deve aprender com a mudança, que a educação aprenda com a ressignificação que estamos sendo impostos, proporcionando reflexões a respeito da experiência social imposta pela pandemia. Com mudanças no planejamento educacional, no uso das tecnologias, nos conteúdos, na didática, nas avaliações, nas relações e na forma de pensar o sentido da educação.

Face ao exposto, apresentamos algumas ações que podem orientar para uma mudança no paradigma educacional. Que as tecnologias utilizadas sejam interfaces de construções conjuntas, potencializando os debates e não a transmissão de conteúdos. Assim como, o pensamento crítico e não o consumo passivo de informações, a criatividade para a cocriação em rede e fora dela, a comunicação efetiva e amorosa, o currículo integrado com a realidade dos estudantes, onde suas vivências sejam consideradas. Atos de currículo multidisciplinares que reúnam professores em uma proposta em comum, projetos que possam ser realizados para encontrar soluções para problemas reais e contemporâneos, avaliações processuais, com recuperações paralelas e tantas outras discussões necessárias para uma educação de qualidade e que se tornam essenciais à formação do cidadão pronto para lidar com o novo mundo que está por vir.

Como diria Nelson Mandela, “a educação é a arma mais poderosa que você pode usar para mudar o mundo”. A narrativa de duas praticantes demonstra que os professores são os grandes atores dessa mudança, a temática Resiliência docente, desafios profissionais e superação nos lembra que "ser professor é sinônimo de resiliência (...)” e “(...) mas eu estou para ver uma classe que supera tantas adversidades e consegue se superar... Viva aos professores”, mencionadas por Graciete e Vanessa, respectivamente. Inspiradas nelas e em tantos professores desse Brasil, acreditamos que sairemos mais fortes do que entramos nessa pandemia, professores resilientes, que criam, resistem e inspiram.

\section{CONSIDERAÇÕES FINAIS}

As tecnologias se tornaram importantes no trabalho didático do professor dentro e fora de sala de aula nos dias atuais. Porém, é preciso estar atento aos equívocos que envolvem o trabalho com tais recursos, muitos acreditam que basta realizar uma transposição das propostas presenciais para que a educação online aconteça, outros acham que as tecnologias substituirão os professores, entre tantos olhares superficiais sobre a temática. O professor ainda é uma figura fundamental, ele é quem deve ser o indivíduo responsável por despertar naquele aluno o interesse pela educação de diferentes formas possíveis, uma espécie de mediador nessa nova relação de escola-tecnologias-cidades-alunos.

Reunimos as narrativas dos docentes em 13 categorias principais e selecionamos algumas narrativas para exemplificar tais temas, são eles: repensar o currículo para uma educação humanista, precarização da profissão docente, saúde dos professores, exclusão social, lógica conteudista da educação, as tecnologias contribuindo para o 
distanciamento social, de forma a evitar o retorno ao presencial, sobrecarga de trabalho com a produção de recursos educacionais, dificuldades financeiras de docentes, relação entre professores e responsáveis, táticas de praticantes para driblar a falta de dados de internet, entrelaçamento entre a vida profissional e a pessoal, retorno seguro das aulas presenciais, resiliência docente, desafios profissionais e superação. Entre essas temáticas, dialogamos com alguns pontos e trouxemos um referencial teórico atual, que debate sobre a educação em tempos de Coronavírus e pandemia.

Afirmamos a incompletude do presente trabalho, recortes e seleções foram feitas, afinal, não nos propomos integrais, mas sim, uma abertura para outras reflexões. Deixamos pistas para que os leitores possam pensar junto e se encontrar nas falas. Quem sabe, implementar propostas levando em consideração os debates tecidos e dialogar conosco, estamos abertos a isso, vamos cocriar! Desejamos uma grande transformação para o mundo pós-pandemia, uma virada, um tempo de trânsito para a educação. Por outro educar, por outras educações!

\section{REFERÊNCIAS}

CERTEAU, Michel de. A invenção do cotidiano: artes de fazer. Petrópolis: Vozes, 1994.

FREIRE, Paulo. Educação como prática da liberdade. Rio de Janeiro: Paz e Terra, 1967.

HINE, C. Virtual Ethnography. London: SAGE Publications, 2000.

LEMOS, André; LÉVY, Pierre. O futuro da internet: em direção a uma ciberdemocracia. São Paulo: Paulus, 2010.

LÉVY, Pierre. Cibercultura. Tradução de Carlos Irineu da Costa. São Paulo: Ed. 34, 1999. Disponível em: < https://books.google.com.br/books?id=7L29Np0d2YcC\&pg=PA11\&hl=pt-BR\&source=gbs_ toc_r\&cad=4\#v=onepage\&q\&f=false $>$ Acesso em: 24 de maio de 2019.

LOTH, Adriana; PRETTO, Luana; OLIVEIRA, Ricardo; ZSCHORNACK, Thiago. As tendências e desafios da web 3.0 à luz da gestão do conhecimento. RISUS - Journal on Innovation and Sustainability, São Paulo, 2019. v. 10, n.1, p37-47.

MERCADO, L. P. L.. Pesquisa Qualitativa On-Line Utilizando a Etnografia Virtual. Revista Teias. Rio de Janeiro, 2012. v. 13, p. 167-181.

MINISTÉRIO DA EDUCAÇÃO. Censo escolar. Brasília, 2020. Disponível em: <http://portal.inep.gov.br/ censo-escolar> Acesso em: 29 abr 2020.

MINISTÉRIO DA SAÚDE. Novo Coronavírus (Covid-19): informações básicas. Brasília, 2020. Disponível em: <http://bvsms.saude.gov.br/component/content/article?id=3135> Acesso em: 09 abr 2020.

MORAN. J.M. A educação que desejamos: novos desafios e como chegar lá. Campinas, SP: Papirus, 2007.

PRETTO, Nelson; BONILLA, Maria Helena; SENA, Ivânia. Educação em tempos de pandemia: reflexões sobre as implicações do isolamento físico imposto pela COVID-19. Salvador: Edição do autor, 2020.

SANTOS, Boaventura de Sousa. A Cruel Pedagogia do Vírus. Coimbra: Almedina, 2020.

SANTOS, Edméa. Pesquisa-formação na cibercultura. 1. ed. Santo Tirso: Whitebooks, 2014. V. 1. 202p.

UNESCO. Suspensão das aulas e resposta à COVID-19. Paris, 2020. Disponível em: <https://pt.unesco.org/ covid19/educationresponse> Acesso em: 22 abr. 2020. 